\title{
A PROBLEMÁTICA DO CABIMENTO NO RECURSO DE AGRAVO DE INSTRUMENTO.
}

Marcelo Farina De Medeiros', ${ }^{1,2}$ Wesley Aparecido Da Silva.

'Universidade de Marília - UNIMAR, Mestrado em Direito, Marília, SP. ${ }^{1,2}$ Universidade do Oeste Paulista UNOESTE, Curso de Direito, Presidente Prudente, SP.

\section{RESUMO:}

O novo Código de Processo Civil - CPCalterou disciplina do recurso de agravo de instrumento, condicionando o seu cabimento à previsão legal da decisão judicial como agravável. Se por um lado tal inovação visa a diminuir o número de recursos nos tribunais e contribuir com a celeridade de resolução dos processos, por outro lado dá ensejo ao problema de se condicionar a apreciação jurisdicional de decisões que possam lesar direitos individuais a hipóteses legais, diante de uma sociedade que vive em constante evolução, uma vez que o legislador não é capaz de prever todas as hipóteses em que a apreciação recursal de determinada decisão interlocutória demande urgência. Surgem, portanto, na doutrina, defensores do cabimento de mandado de segurança em face das decisões urgentes não agraváveis, ou, a hipótese de se abandonar a taxatividade do cabimento para a adoção da interpretação analógica. Tais institutos, no entanto, desvirtuam a finalidade do legislador e se aproximam da regra então vigente na lei processual revogada. 0 presente trabalho, por meio do método dedutivo, baseando-se em pesquisa bibliográfica e normativa, aborda a problemática do cabimento do recurso de agravo de instrumento, na lei vigente, tecendo considerações críticas e trazendo sugestões.

Palavras chave: Recurso; Agravo de instrumento; Cabimento.

\section{THE ISSUE OF LEGAL PROVISION OF JUDICIAL DECISIONS CHALLENGEABLE BY INTERLOCUTORY} APPEAL

\begin{abstract}
:
The new Civil Procedure Code changed the interlocutory appeal rules, making their pertinence to the legal provisions. On the one hand such innovation aims to reduce the number of legal remedies in the courts and contribute to fast resolution of cases, but on the other hand it causes the problem of create condition the judicial review of decisions that may harm individual rights to legal provision. It doesn't works in a society that lives in constant evolution, since the legislature is unable to predict all cases in which the appellate consideration of certain interlocutory decision demands urgency. Therefore,come doctrine that advices injunction against urgent decisions that the law forbid interlocutory appeal. Arise too doctrine that advices analogical interpretation to legal provisions. These institutions, however, detract from the purpose of the legislature and then approach the current rule in procedural law repealed. This academic research, by the deductive method, based on literature and normative research, study the issue of legal provision of judicial decisions challengeable by interlocutory appeal,weaving critical arguments and bringing suggestions considerations.
\end{abstract}

Key words:Legal remedy; Interlocutory appeal; Legal provision. 


\section{INTRODUÇÃO}

A atividade jurisdicional é de suma importância para manter a paz social no Estado Democrático de Direito, uma vez que atua como uma das esferas do Poder Público, visando a assegurar a autoridade da norma. Isso para dar previsibilidade do que é aceito, ou reprovado nas relações sociais, gerando segurança jurídica. Ocorre, no entanto, conforme o quadro operacional gizado pelo Barão de Montesquieu, que "para que não se possa abusar do poder é preciso que, pela disposição das coisas, o poder contenha o poder" ${ }^{1}$, logo, como liberdade decorrente do Estado Democrático de Direito em conjunto com a previsão constitucional dos Tribunais tem-se, como princípio recursal, o duplo grau de jurisdição como "[...] um complexo de garantias mínimas contra o subjetivismo e o arbitrio dos que têm poder de decidir" 2 .

Os pronunciamentos jurisdicionais, na fase de conhecimento do processo civil, são os despachos, decisões interlocutórias e a sentença (art. 203, CPC). Os despachos não têm conteúdo decisório, não interferindo na esfera subjetiva dos litigantes, logo, são irrecorríveis (art. 1001, (PC). Já a sentença e as decisões interlocutórias são pronunciamentos de conteúdo decisório, logo a lei assegura o duplo grau de jurisdição, por meio de recursos. Os recursos que visam a impugnar as sentenças e decisões interlocutórias são a apelação (art. 1009, CPC) e o agravo de instrumento (art. 1015, CPC), sendo este restrito a algumas decisões interlocutórias previstas em lei como agraváveis. As demais decisões interlocutórias, não agraváveis, ante a nova sistemática processual não são impugnáveis de imediato, só podendo ser discutidas posteriormente, em preliminar de razões, ou contrarrazões de apelação (art. 1009, § 1ํ, CPC).

A disciplina legal do recurso de agravo de instrumento nunca foi pacífica, uma vez que enquanto a fase de conhecimento do processo civil gera uma sentença, pode gerar diversas decisões interlocutórias. Assim, pode ocorrer que de um único processo de conhecimento resulte um recurso de apelação, porém diversos recursos de agravo de instrumento. Por isso esse recurso sofreu diversas alterações no decorrer das mudanças legislativas, desde a edição do Código de Processo Civil de 1973, sendo a mais recente e objeto do presente trabalho a alteração promovida por meio da entrada em vigor do novo código de processo civil, lei 13.105 de 16 de março de 2015.

A mudança mais impactante advinda da nova lei processual, em relação ao recurso de agravo de instrumento, foi a imposição de previsão legal das hipóteses de cabimento desse recurso. A partir da entrada em vigência da lei 13.105, de 16 de março de 2015, somente cabe agravo de instrumento contra as decisões que estiverem previstas nos incisos do artigo 1.015, do Código de Processo Civil - CPC, ou em outros dispositivos legais, como por exemplo,a previsão do artigo 1037, § 13, inciso I, do CPC. A necessidade de previsão legal para o cabimento do agravo, como tentativa de reduzir o número de processos nos Tribunais, tem gerado críticas positivas e negativas, e também dúvidas sobre o comportamento dos advogados diante de eventual decisão interlocutória não agravável, que traga prejuízo à parte, necessitando de urgência na suarevisão. 0 presente trabalho busca contribuir com as críticas, mediante pesquisa bibliográficarealizada pelo método dedutivo.

\section{METODOLOGIA:}

Para cumprir com seu objetivo, o presente trabalho segue o métododedutivo, com emprego de pesquisa doutrinária, legal e jurisprudencial acerca do objeto do estudo.

\section{BREVE EVOLUÇÃO HISTÓRICA DO CABIMENTO DO AGRAVO DE INSTRUMENTO}

A palavra agravo carrega o significado de afronta, sendo ela positiva ou negativa, a depender do caso concreto.Embora a palavra agravo seja utilizada genericamente pelo Código de

\footnotetext{
${ }^{1}$ MONTESQUIEU. Charles Louis. Do Espírito das Leis: 110 livro, capítulo IV.

${ }^{2}$ PASSOS, Calmon de. Direito, Poder, Justiça e Processo, Rio de Janeiro: Forense, 1999, p. 69. 
Processo Civil para conceituar diversos recursos, o presente trabalho aborda especificamente o agravo de instrumento, meio pelo qual a parte que não se conforma com uma decisão interlocutória proferida por juiz de primeiro grau, busca anulá-la, ou reforma-la, por meio da decisão de um órgão hierarquicamente superior.

O agravo sofreu diversas mudanças no decorrer da evolução do direito processual civil.Seu surgimento se deu no direito português, no reinado de D. Afonso III, quando a legislação portuguesa reclamava a necessidade de um recurso que atacasse somente determinado objeto e não de toda a lide, como na apelação.Em um primeiro momento surgiu o agravo por petição e o agravo de instrumento, que supriam a necessidade apontadae,posteriormente, novas modalidades de agravo foram surgindo e agregando-se ao sistema processual português, como agravo ordinário, o agravo de ordenação não guardada e o agravo no auto do processo. $\mathrm{O}$ agravo de instrumento brasileiro teve inspiração no agravo no auto do processo português. No Código de Processo Civil nacional, de 1939, foi abarcado o agravo no auto do processo, com a intenção de evitar a preclusão da impugnação das decisões interlocutórias, juntamente com o agravo de petição, que era o meio processual viável para impugnar decisões extintivas do processo, sem a resolução do mérito. Naquela época o agravojá tinha limitações, cabendo somente em face de algumas decisões ${ }^{3}$.

Com o código de processo civil nacional, de 1973, houve a expansão do cabimento do agravo de instrumento. Vulgarmente poderia se dizer quetoda decisão interlocutória proferida por juiz de primeiro grau era recorrível por meio de agravo. O Código de Processo Civil de 1973 também avançou ao diferenciar sentença e decisão interlocutória, prevendo o cabimento do recurso de apelação às sentenças, fossem com ou sem a resolução do mérito. $O$ código passado sofreu, entre várias microrreformas, a promovida por meio da lei 11.187, de 19 de outubro de 2005, diferenciando as hipóteses de cabimento entre as modalidades de agravo, oretido e agravo de instrumento.

O agravo retido era a regra, cabível em face quase todas as decisões interlocutórias, dispensando o preparo recursal, pois ficava retido no processo, aguando até que a instancia superior tomasse conhecimento dele, o que deveria ser pleiteado em preliminar de razões ou contrarrazões de apelação. No tocante às decisões interlocutórias susceptíveis de causar à parte lesão grave e de difícil reparação, assim como aquelas posteriores à sentença, era cabível a interposição do agravo por instrumento, modalidade que demandava a formação do instrumento com cópias de peças obrigatórias e preparo recursal, pois, tal como hoje, o recurso era endereçado ao tribunal competente pelo julgamento do seu mérito.

O Código de processo civil de 2015 extinguiu a modalidade do agravo retido, mantendo o agravo de instrumento.Porém, pode-se dizer que houve uma "volta ao passado", pois a partir da sua vigência o cabimento do aludido recurso foi limitado para hipóteses pré-definidas em lei, conforme previsão expressa do artigo 1.015:

Art. 1.015. Cabe agravo de instrumento contra as decisões interlocutórias que versarem sobre:

I - tutelas provisórias;

II - mérito do processo;

III - rejeição da alegação de convenção de arbitragem;

IV - incidente de desconsideração da personalidade jurídica;

$\mathrm{V}$ - rejeição do pedido de gratuidade da justiça ou acolhimento do pedido de sua revogação;

VI - exibição ou posse de documento ou coisa;

VII - exclusão de litisconsorte;

\footnotetext{
${ }^{3}$ MAGLIAVACCA, Carolina Moraes. Do recurso de agravo no processo civil brasileiro. 19 Mar. 2007. Disponível em: <http://www.tex.pro.br/home/artigos/79-artigos-mar-2007/5569-do-recurso-de-agravo-no-processo-civil-brasileiro> Acesso em: 07 Ago. 2016. 
VIII - rejeição do pedido de limitação do litisconsórcio;

IX - admissão ou inadmissão de intervenção de terceiros;

$X$ - concessão, modificação ou revogação do efeito suspensivo aos embargos à execução;

$X I$ - redistribuição do ônus da prova nos termos do art. 373, § 10;

XII - (VETADO);

XIII - outros casos expressamente referidos em lei.

Parágrafo único. Também caberá agravo de instrumento contra decisões interlocutórias proferidas na fase de liquidação de sentença ou de cumprimento de sentença, no processo de execução e no processo de inventário.

Vê-se, portanto, que o intuito do legislador foi claramente restringir o cabimento do recurso de agravo de instrumento às hipóteses expressamente previstas em lei.

\section{RECORRIBILIDADE DAS DECISÕES INTERLOCUTÓRIAS EAS CONSEQUENTES MITIGAÇÃO DO PRINCÍPIO DA UNICIDADE E ALTERAÇÃO DA REGRA DE PRECLUSÃO:}

$O$ cabimento é requisito de admissibilidade que deve ser examinado em duas dimensões: a previsão legal do recurso e sua adequação. Assim, previsto o recurso em lei, cumpre-se verificar se é ele o meio adequado a combater a decisão da qual o legitimado a recorrer não se conforma.

A doutrina identifica três princípios recursais correlatos ao estudo pressuposto de admissibilidade recursal do cabimento: o princípio da fungibilidade, o princípio da unicidade (também conhecido por unirrecorribilidade, ou singularidade) e o princípio da taxatividade. Em rigor técnico, princípio seria somente o da fungibilidade, uma vez que a singularidade e a taxatividade são regras. Segundo Barbosa Moreira, a regra da unicidade reza que para cada decisão judicial há um recurso adequado a combatê-la e somente um ${ }^{4}$. Assim, nas instâncias ordinárias não é possível a utilização simultânea de dois recursos contra a mesma decisão judicial.Ocorre que aideia de limitar o recurso de agravo às hipóteses previstas em lei gerou uma mitigação à regra da unicidade, uma vez que não se pode mais afirmar genericamente que o recurso de agravo é cabível para impugnar as decisões interlocutórias. Isto porque o recurso de agravo de instrumento serve para impugnar as decisões interlocutórias agraváveis,assim entendidas aquelas previstas em lei como impugnáveis por agravo, contudo, as decisões não agraváveis somente podem ser impugnadas em preliminar de razões, ou contrarrazões de apelação, conforme a regra do artigo $1009, \S 1$ 1․ do $C P C^{5}$. O recurso de apelação, portanto, serve para impugnar tanto a sentença, como as decisões interlocutórias não agraváveis.

A delimitação do cabimento do recurso de agravo de instrumento e a consequente ampliação do objeto do recurso de apelação, para abranger a impugnação das decisões interlocutórias não agraváveis, gerou a postergação da preclusão no tocante à discussão sobre tais decisões. O código de processo civil vigente permite que a parte contrária a umaou mais decisões interlocutórias que não estiverem previstas em lei como agraváveis,possa ficar silente, manifestando-se somente em preliminar de apelação, aí sim, sob pena de preclusão.Conclui-se, portanto, que a nova disciplina do agravo tem repercussão não só na mitigação do princípio da unicidade, mas também na disciplina da preclusão quanto a impugnação das decisões interlocutórias, uma vez que as interlocutórias agraváveis devem ser impugnadas no prazo de 15 (quinze) dias, contados da sua publicação, sob pena de preclusão temporal, ao passo que no

\footnotetext{
${ }^{4}$ MOREIRA, José Carlos Barbosa. Comentários ao Código de Processo Civil. 11a ed. rev. e atual. Rio de Janeiro: Forense, 2003 , v. 5, p. 249. ${ }^{5}$ Art. 1.009. [...].

$\S 1^{\circ}$ As questões resolvidas na fase de conhecimento, se a decisão a seu respeito não comportar agravo de instrumento, não são cobertas pela preclusão e devem ser suscitadas em preliminar de apelação, eventualmente interposta contra a decisão final, ou nas contrarrazões.
} 
tocante às decisões interlocutórias não agraváveis há a postergação da preclusão ao momento do oferecimento das razões, ou contrarrazões de apelação, sob pena de preclusão consumativa.

\section{CRÍTICAS À RESTRIÇÃO DO CABIMENTO DO AGRAVO DE INSTRUMENTO:}

Ao postergar a recorribilidade das decisões interlocutórias não urgentes à eventual interesse recursal diante do resultado da sentença, o legislador aponta no sentido de mitigar o número de recursos a serem apreciados nos tribunais de segundo grau. $O$ intuito da restrição do cabimento do recurso de agravo de instrumento é o de reduzir o numero de recursos nos Tribunais. A possibilidade de poder atingir a uma decisão interlocutória nas razões, ou contrarrazões de apelação faz com que um único recurso já englobe temas que antes eram discutidos em recursos autônomos.Por outro lado, remeter a apreciação jurisdicional a hipóteses previamente previstas em lei nunca foi visto com bons olhos, haja vista que o legislador não é capaz de prever todas as situações processuais que demandem urgência no caso concreto.

A nova disciplina do cabimento do recurso de agravo de instrumento não resolve as situações de decisões interlocutórias não previstas em lei como agraváveis, mas cuja ilegalidade traga urgência no caso concreto. O código de processo civil impõe à parte prejudicada tais decisões a esperar até que a fase de conhecimento chegue ao fim, para só então surgir a possibilidade de questionar a decisão em preliminar de apelação. O privilégio da celeridade, neste caso,pode gerar insegurança jurídica. Imagine-se, por exemplo, o credor de uma empresa que lhe move uma execução já garantida por penhora, em fase final de satisfação do seu direito, quando sobrevém o deferimento do processamento do pedido de recuperação desta empresa. Segundo o artigo 6으, da lei 11.101, de 09 de fevereiro de 2005, todas as execuções movidas em face da empresa devem ser suspensas, diante do processamento da sua recuperação judicial. Como a decisão judicial que determina a suspensão da execução, neste caso, não está prevista em lei como agravável, o credor não tem como impugná-la e independentemente da sua situação financeira terá de esperar ao menos por 180 (cento e oitenta) dias de suspensão. Outro exemplo é o caso do juiz que não reconhecer a sua incompetência, seja absoluta, ou relativa, suprimindo o direito de a parte ter rápida solução do litígio, pois a incompetência gera a nulidade das decisões que tragam prejuízo à parte, ou impondo à parte o dever ilegal de litigar em comarca diversa daquela que seria a competente, trazendo-lhe prejuízo. Em ambos os exemploso não cabimento do agravo de instrumento caracteriza exclusão legal da apreciação jurisdicional da lesão, ou ameaça a direito da parte prejudicada.

Diante de decisões urgentes não agraváveis surgem duas opões ainda não bem definidas na prática: restaria ao legitimado impetrar mando de segurança, ou caberia uma interpretação extensiva das hipóteses de interlocutórias agraváveis?

Qualquer das situações enseja estudo mais aprofundado. A lei 12.016, de 07 de agosto de 2009, proíbe a concessão de mandado de segurança em face de decisão judicial da qual caiba recurso com efeito suspensivo. As decisões interlocutórias não agraváveis são impugnáveis por apelação (art. 1009, § 1ํ, CPC), que tem efeito suspensivo (art. 1012, caput, CPC), logo, não admitem impugnação via mandado de segurança.Ainda que se admitisse, a intenção do legislador de reduzir o numero de processos nos Tribunais estaria frustrada, pois somente ocorreria a substituição do agravo de instrumento pelo mandado de segurança. A outra solução, de interpretação extensiva das hipóteses de cabimento, mediante analogia, vai contra a intenção do legislador, que claramente optou por hipóteses taxativas de cabimento do recurso, para gerar celeridade processual. A extensão analógica retrocederia às regras da lei 11.187, de 19 de outubro de 2005, na qual as decisões consideradas urgentes, susceptíveis de causar à parte lesão grave de difícil reparação eram impugnáveis por agravo de instrumento, ao passo que as demais eram impugnáveis por agravo retido, que tinham de ser reiterados em preliminar de apelação (art. 523, do CPC de 1973). A também vai contra a intenção do legislados de atingir a redução do número de 
recursos nos Tribunais.Além disso, firmada tal possibilidade de interpretação analógica, pode acontecer de que um Tribunal pacifique jurisprudência no sentido do cabimento do recurso de agravo de instrumento em face de determinada decisão interlocutória não agravável, gerando o risco de se aplicar, também por analogia, a preclusão temporal à impugnação de tal decisão, caso a parte não agrave por instrumento, deixando para impugnar a decisão na apelação. Tal fato não pode acontecer, pois se a inafastabilidade da jurisdição proíbe que a lei exclua da apreciação do Poder Judiciário lesão, ou ameaça a direito, quiçá também veda que interpretação analógica de um determinado Tribunal o faça.

\section{CONCLUSÃO}

Por força do princípio da inafastabilidade da jurisdição, não é possível que a regra da taxatividade das hipóteses de cabimento do recurso de agravo de instrumento, instituída por meio da lei 13.105, de 16 de março de 2015, exclua da apreciação recursal lesão advinda de decisão interlocutória que possa causar à parte lesão irreparável, ou de difícil reparação, simplesmente pela falta de previsão legal. Há que se ter como acertada, portanto, a tese de ampliação analógica das hipóteses de cabimento do recurso de agravo de instrumento, haja vista que a lei 12.016/2009 veda o mandado de segurança em face das decisões interlocutórias proferidas em processo judicial, impugnáveis por apelação com efeito suspensivo. A ampliação analógica das hipóteses de decisões interlocutórias agraváveis por instrumento, contudo, não pode gerar jurisprudência capaz de criar preclusão temporal, quando a parte que desconhecendo a posição de um determinado Tribunal resolva seguir a regra legal e postergar a impugnação às razões, ou contrarrazões de apelação, haja vista que tal situação prejudicaria os procuradores que residem em Estados, ou Região diversa daquele Tribunal e desconhecem a sua jurisprudência, gerando, em última análise, a exclua da apreciação jurisdicional da lesão sofrida pela parte, o que é vedado pela Constituição Federal (art. 5, XXXV).

\section{REFERÊNCIAS}

BRASIL, Constituição da República Federativa do Brasil de 1988. Disponível em: http://www.planalto.gov.br/ccivil_03/Constituicao/Constituicao.htm. Acesso em 07 ago. 2016.

.Lei 11.187, de 19 de outubro de 2005. Disponível em: http://www.planalto.gov.br/ccivil_03/_ato2004-2006/2005/lei/l11187.htm. Acesso em 07 ago. 2016.

Lei 12.016, de 07 de agosto de 2009. Disponível em: http://www.planalto.gov.br/ccivil_03/_ato2007-2010/2009/lei/l12016.htm. Acesso em 07 ago. 2016.

Lei 13.105, de 16 de março de 2015. Disponível em: http://www.planalto.gov.br/ccivil_03/_ato2015-2018/2015/lei/l13105.htm. Acesso em 07 ago. 2016.

MAGLIAVACCA, Carolina Moraes. Do recurso de agravo no processo civil brasileiro. 19 Mar. 2007. Disponível em: <http://www.tex.pro.br/home/artigos/79-artigos-mar-2007/5569-do-recurso-deagravo-no-processo-civil-brasileiro> Acesso em: 07 Ago. 2016.

MARINONI, Luiz Guilherme; MITIDIERO, Daniel; ARENHART, Sérgio Cruz. Novo curso de Processo Civil, vol. 02, São Paulo: Revista dos Tribunais, 2015.

MONTESQUIEU. Charles Louis. Do Espírito das Leis: 11 livro, capítulo IV. 
MOREIRA, José Carlos Barbosa. Comentários ao Código de Processo Civil, vol. 05, 11a ed. rev. e atual. Rio de Janeiro: Forense, 2003.

PASSOS, Calmon de. Direito, Poder, Justiça e Processo, Rio de Janeiro: Forense, 1999.

TALAMINI, Eduardo. Agravo de instrumento: hipóteses de cabimento no CPC/15.Disponível em:http://www.migalhas.com.br/dePeso/16,MI236240,41046.Agravo+de+instrumento+hipoteses + de+cabimento+no+CPC15. Acesso em 07 ago. 2016. 